\title{
Bridging the intervention-implementation gap in primary health care delivery: the critical role of integrated implementation research
}

\author{
John Koku Awoonor-Williams* and Ebenezer Appiah-Denkyira
}

\begin{abstract}
For national and local leaders to achieve universal health coverage, a new approach or technique to gathering evidence and understanding the context and context that influence the outcome of the study and goes beyond the quantitative results of the clinical trials and pilot projects is important. The Doris Duke Charitable Foundation's African Health Initiative (AHI) was designed to produce this type of knowledge through embedding implementation research into Population Health Implementation and Training (PHIT) partnership projects in five countries (Ghana, Mozambique, Rwanda, Tanzania, and Zambia) with the goal of improving primary health care and population health. In Ghana, this integration of research into implementation has contributed to the successful testing, adaptation and implementation of the Community-based Health Planning and Services (CHPS) model (The Navrongo Pilot Project), with results from the AHI-funded work informing national scale-up of effective practices. Further application of implementation science methods and frameworks to study cross-project lessons also produced the evidence needed by national and local decision makers on how and why different intervention components were successful and where and how local context drove implementation and adaptation. Crossproject research also identified effective approaches across diverse settings for building capacity for data driven improvement, coaching and mentoring clinicians and researchers, developing locally appropriate interventions to reduce neonatal mortality, and integrating implementation research to inform local implementers and researchers in more effective strategies to strengthen health systems and improve health services and population health. Evidence has already shown the potential for this type of work to accelerate regional learning and spread of successful interventions to achieve targeted health goals more efficiently, better enabling countries to achieve the ambitious, but important, U.N. Sustainable Development Goals.
\end{abstract}

Keywords: Africa, Health systems strengthening, Primary health care, Maternal, newborn, and child health, Ghana, Mozambique, Rwanda, Tanzania, Zambia

\section{Background}

The last century has seen remarkable advances in the knowledge of how to better prevent and treat many of the conditions that are major causes of suffering and death around the world. The U.N. Millennium Development Goals helped spur considerable progress in reducing deaths caused by infectious diseases such as HIV, malaria and TB, as well as in addressing major

\footnotetext{
* Correspondence: kawoonor@gmail.com

Ghana Health Service, Private Mail Bag, Ministries Post Office, Accra, Ghana
}

causes of maternal and child deaths [1]. Efforts to strengthen primary health care in low- and middleincome countries have contributed to these gains, by improving access to needed care among the most vulnerable [2]. However, this success has been tempered by variability in progress between and within countries, lack of global access to effective primary care, the rise in non-communicable diseases and the chasm between what interventions we know work and what services people actually receive [3, 4]. Due to a decrease in resources available to fund health care delivery, 
particularly for low and middle income countries, more effective and efficient implementation of interventions is required. In addition, while strong primary care delivery systems can serve as effective platforms for further health system strengthening initiatives, the recent Ebola outbreak made apparent the weaknesses of health systems that are not resilient and people-centered [5-8].

For national and local leaders to continue making progress while addressing these challenges, a new type of evidence is needed that goes beyond the results of clinical trials and pilot projects. Green and Glasgow wrote, "if we want more evidence-based practice we need more practice-based evidence" [9]. This approach increases the probability that evidence from research on effective interventions is useful, relevant and able to inform polices needed to translate this knowledge into action, reducing the chasm between what works and what is delivered, a major cause of suffering and waste globally $[10,11]$.

\section{Better knowledge to drive quality universal health coverage} The articles in this supplement of BMC Health Services Research offer a unique opportunity to learn from the African Health Initiative (AHI) funded projects, which focused on strengthening the primary health care delivery systems at the district or provincial levels in five sub-Saharan African countries to improve population health and serve as platforms for further health system strengthening work [12]. Teams from across the projects, representing a range of stakeholders and disciplines, have applied implementation research methodologies to extract learnings from common intervention components and implementation approaches. This type of evidence serves as the bridge between the current know-do gap and is core to the development of resilient people-centered health systems that deliver quality universal health coverage. The articles in this supplement are part of a growing body of implementation research that has increased the knowledge base on how to better adapt and implement interventions effectively across a range of contexts and to cull generalizable lessons from the implementation of interventions developed and tested in other settings [13, 14]. Parry and colleagues argue that the study of health care improvement initiatives needs to answer not simply if an intervention worked, but also apply a theory-driven evaluation approach to provide evidence on how and in what contexts it worked and where change was needed [15]. The supplement authors' use of mixed methods and implementation research frameworks such as the Consolidated Framework for Implementation Research, is a step towards generating rigorous and more actionable knowledge to strengthen health systems in the five African contexts and to promulgate the translation of knowledge into practice [16-18].

\section{Better measurement, better improvement}

The cross-site research discussed in this supplement reveals effective methods to improve utilization of routine data for improved decision-making. Globally, there is recognition that while data collection and reporting has increased, a gap remains between quality and availability of health information and use by providers and program managers to identify gaps and drive improvement at the clinical and systems level [19-22]. The AHI projects utilized various approaches in the gathering and analysis of health information to inform policy across diverse settings, which helped to improve the availability and quality of data for ascertaining the successful implementation of the interventions amidst changing the culture and capacity for the improvement and use of data for decision making [16-18, 23, 24]. These lessons are important for both policymakers choosing how and where to effectively invest in routine Health Information Systems (HIS), and for HIS users attempting to bridge the gap between data collection and data use to improve the delivery of quality health services [25].

\section{Better investment in people}

The AHI projects were also unique in emphasizing the integration of implementation research into the frontlines, and building capacity of implementers and local researchers within the countries to drive this work during the project periods and for the future [26]. Locally designed and driven research is a key approach to ensuring that health services and delivery processes are more relevant to local challenges and also increase ownership and drive translation from research into practice. The emphasis on implementation research enabled researchers to better understand outcomes and impact, as well as how and why different interventions worked and where variability could inform future adaptation and spread [23, 24]. Further investment in people was seen in the mentoring work focused on increasing capacity in clinicians and managers to be more effective and in strengthening data utilization capacity in targeted data consumers $[23,24]$.

\section{The Ghana perspective}

In Ghana, this integration of research into implementation has led to the successful testing, adaptation and implementation of the Community-based Health Planning and Services (CHPS) model (The Navrongo Pilot Project), with results from the AHI-funded work informing national scale-up of effective practices. These included the successful implementation and impact of the Ghana Essential Health Intervention Program (GEHIP) on under-five mortality rates and improvements in facilitybased maternal and neonatal survival among emergency cases through innovations in improving the referral 
service [27] (Awoonor-Williams, personal communications, 2015). Further changes in the Ghanaian health system, including the National Health Insurance Scheme and decentralization of responsibility and authority, offer current and future opportunities for ongoing integrated research and application of effective interventions. Our experiences have also been informed by and contributed to the broader learning across the AHI-funded projects in areas from neonatal mortality reduction to improving data utilization to drive improvement, research capacity building, and the role of mentoring and coaching to improve quality of care.

\section{Conclusion}

This supplement is an example of applying these emerging methodologies across the five AHI projects to produce the evidence needed by national and local decision makers on how and why different intervention components are successful, and equally important insights into where and how local context drive implementation and adaptation. Although the implementation research outcomes described in this supplement do not speak to the traditional population health impact metrics as a measure of success, they provide insight into the acceptability, adoption and early evidence of sustainability of interventions, critical information for policy makers and frontline implementers as they work to achieve stronger health systems and better primary health care [28]. The potential for initiatives like AHI to accelerate regional learning and the spread of effective implementation approaches is enormous, and similar efforts are needed to help countries more rapidly achieve the much broader agenda of the U.N. Sustainable Development Goals, particularly Goal \#3, which has health systems strengthening at its core.

\section{Key messages}

- Embedded research helps to articulate the evidence associated to two or more sub units of analysis of a phenomenon. Embedded implementation research is effective in producing usable evidence for policy makers and managers able to be translated into strategies and spread at the national and subnational levels

- Embedded research although has been found to be useful in understanding the implementation of health interventions, however, not much has been written about it. Whereas at the same time the need for clear research evidence to improve health interventions continues to be a gap and the subject of academic and policy interest. Embedded implementation will fill this knowledge gap by giving an insight into how local context influence the implementation and adaptation to the project.

- Integration of implementation research can build local capacity of implementers and encourage them to be more responsive to scientific evidence which will help them to deliver better health care within resource-constrained setting.

- Despite differences in the Africa Health Initiative projects and countries, key lessons in how to build capacity for embedded implementation research, increase data utilization and improve primary health care offer important insights for other countries working on how to achieve quality universal health coverage. Capacity building, coaching and mentoring of implementers in undertaking embedded implementation research is unique in terms of its contribution to helping frontline managers to understand the process and content that increase the success of implementation of health intervention. In this specific project, it further helps them to articulate the outcomes and impact of the intervention and timely address the inherent challenges of implementation.

\section{Abbreviations}

AHI: African Health Initiative; CHPS: Community-based Health Planning and Services; GEHIP: Ghana Essential Health Intervention Program;

PHIT: Population Health Implementation and Training partnerships

\section{Acknowledgements}

We would like to thank Dr. Lisa R. Hirschhorn for her input and feedback and Jordan Downey for editing and formatting assistance. Funding for this work was provided by the Doris Duke Charitable Foundation under the PHIT African Health Initiative (Grant \#2009058B) as well as by Comic Relief (Grant \#112475).

\section{Funding}

The publication cost of this article was funded by the African Health Initiative of the Doris Duke Charitable Foundation.

Availability of data and materials Not applicable

\section{About this supplement}

This article has been published as part of BMC Health Services Research Volume 17 Supplement 3, 2017: Implementation science as an essential driver for sustainable health systems strengthening interventions: Lessons learned across the five-country African Health Initiative. The full contents of the supplement are available online at https://bmchealthservres.biomedcentral.com/articles/supplements/volume-17-supplement-3.

Authors' contributions

Both authors have read and approved the final manuscript.

Authors' information

John Koku Awoonor-Williams, MD, MPH, MPP, PhD; Ebenezer Appiah Denkyira, MD, MPH.

Ethics approval and consent to participate

Not applicable

Consent for publication

Not applicable

Competing interests

The authors declare that they have no competing interests.

\section{Publisher's Note}

Springer Nature remains neutral with regard to jurisdictional claims in published maps and institutional affiliations. 
Published: 21 December 2017

\section{References}

1. United Nations, 2015. The Millennium Development Goals Report., p.72. Available at: https://visit.un.org/millenniumgoals/2008highlevel/pdf/MDG_ Report_2008_Addendum.pdf.

2. Kruk ME, et al. The contribution of primary care to health and health systems in low- and middle-income countries: a critical review of major primary care initiatives. Soc Sci Med. 2010;70(6):904-11.

3. Das J, Hammer J. Quality of primary Care in low-Income Countries: facts and economics. Annual Review of Economics. 2014;6(1):525-53. Available at: https://doi.org/10.1146/annurev-economics-080213-041350

4. Primary Health Care Performance Initiative 2015, viewed 5 August 2016. Available at: http://www.phcperformanceinitiative.org/.

5. Kruk ME, et al. What is a resilient health system? Lessons from Ebola. Lancet. 2016;385(9980):1910-2. Available at: https://doi.org/10.1016/S01406736(15)60755-3

6. World Health Organization, 2015. New partnership to help countries close gaps in primary health care. pp.2015-2017. Available at: http://www.who. int/mediacentre/news/releases/2015/partnership-primary-health-care/en/.

7. Scott V, Crawford-Browne S, Sanders D. Critiquing the response to the Ebola epidemic through a Primary Health Care Approach. BMC Public Health. 2016;16(1):410. Available at: http://bmcpublichealth.biomedcentral.com/ articles/10.1186/s12889-016-3071-4

8. Perry, H.B. et al., 2016. Community health worker programmes after the 2013-2016 Ebola outbreak. Bulletin of the World Health Organization, (September 2015), pp.551-553.

9. Green LW, Glasgow RE. Evaluting the relevance, generalizability and applicability of research. Evalaution and the Health Professional. 2006;29(1):126-53.

10. Zachariah $\mathrm{R}$, et al. Is operational research delivering the goods? The journey to success in low-income countries. Lancet Infectious Dis. 2012;2(5):415-21.

11. Sampson UKA, et al. Implementation research the fourth movement of the unfinished translation research symphony. Glob Heart. 2016;11(1):153-8.

12. Bassett MT, et al. From the ground up: strengthening health systems at district level. BMC health services research, 13 Suppl. 2013;2(Suppl 2):S2. Available at: http://www.pubmedcentral.nih.gov/articlerender.fcgi?artid= 3668220\&tool=pmcentrez\&rendertype $=$ abstract

13. Peters $\mathrm{DH}$, et al. Implementation research: what it is and how to do it: implementation research is a growing but not well understood field of health research that can contribute to more effective public health and clinical policies and programmes. Thi. Br J Sports Med. 2014;48(8):731-6. Available at: http://bjsm.bmj.com/cgi/doi/10.1136/bmj.f6753

14. Maru $D$, et al. Crossing the quality chasm in resource-limited settings. Glob Health. 2012;8:1.

15. Parry GJ, et al. Recommendations for evaluation of health care improvement initiatives. Acad Pediatr. 2013;13(6 SUPPL):S23-30.

16. Gimbel, S. et al., 2017. Improving data quality across 3 sub-Saharan African countries using the consolidated framework for implementation research (CFIR): results from the African health initiative. BMC Health Services Research, 2017 Vol 17 Suppl 3. S6.

17. Sherr, K. et al, 2017. Measuring Health Systems Strength and its Impact: Experiences from the African Health Initiative. BMC Health Services Research, 2017. Vol 17 Suppl 3. S4.

18. Magge, H. et al., 2017. Tackling the hard problems: implementation experience and lessons learned in newborn health from the African health initiative. BMC Health Services Research, 2017. Vol 17 Suppl 3. S5.

19. Tekabe, B., Nkosinathi, M. \& Vikram, R., 2009. Data utilization and evidencebased decision making in the health sector : survey of three Indian states. (27). Available at: http://documents.worldbank.org/curated/en/2009/04/ 11672890/data-utilization-evidence-based-decision-making-health-sectorsurvey-three-indian-states.

20. Foreit, K., Moreland, S. \& LaFond, a, 2006. Data demand and information use in the health sector conceptual framework., pp.1-19. Available at: http:// www.cpc.unc.edu/measure/publications/ms-06-16a.

21. Chan $\mathrm{M}$, et al. Meeting the demand for results and accountability: a call for action on health data from eight global health agencies. PLoS Med. 2010;7(1):5-8.

22. Handley K, et al. An inflection point for country health data. Lancet Glob Health. 2015;3(8):e437-8.
23. Manzi, A. et al., 2017. Mentorship and coaching to support strengthening healthcare systems: lessons learned across the five population health implementation and training partnership projects in sub-Saharan Africa. BMC Health Services Research, 2017. Vol 17 Suppl 3. S2.

24. Wagenaar, B. et al., 2017. Data-driven quality improvement in low-and middle-income country health systems: lessons from seven years of implementation experience across Mozambique, Rwanda, and Zambia. BMC Health Services Research, 2017. Vol 17 Suppl 3. S7.

25. Nutley, T. \& Reynolds, H.W., 2013. Improving the use of health data for health system strengthening., 1, pp.1-10.

26. Hedt-Gauthier, B.L. et al., 2017. Research capacity building integrated into PHIT projects: leveraging research and research funding to build national capacity. BMC Health Services Research, 2017. Vol 17 Suppl 3. S3.

27. Awoonor-Williams, J.K., Phillips, J.F. \& Bawah, A.A., 2015. Catalyzing the scaleup of community-based primary healthcare in a rural impoverished region of northern Ghana. Int J Health Planning and Manage, p.n/a-n/a. Available at: https://doi.org/10.1002/hpm.2304.

28. Peters, D.H., Adam, T. \& Alonge, O., 2013. Implementation research : what it is and how to do it., 6753(November), pp.1-7. Available at: https://doi.org/ 10.1136/bmj.f6753.

\section{Submit your next manuscript to BioMed Central and we will help you at every step:}

- We accept pre-submission inquiries

- Our selector tool helps you to find the most relevant journal

- We provide round the clock customer support

- Convenient online submission

- Thorough peer review

- Inclusion in PubMed and all major indexing services

- Maximum visibility for your research

Submit your manuscript at www.biomedcentral.com/submit
C) Biomed Central 